Research Article

\title{
Biosorption of Cadmium by Fungi Isolated from Bharalu River, Assam
}

\author{
Deka Dipannita ${ }^{1}$, Bora Pinky ${ }^{1}$, Nirjanta N. Devi ${ }^{1 *}$, Chabukdhara Mayuri ${ }^{2}$ \\ ${ }^{1}$ Department of Molecular Biology and Biotechnology, Cotton University, Guwahati 781001, Assam, India \\ ${ }^{2}$ Department of Environmental Biology and Wildlife Sciences, Cotton University, Guwahati 781001, Assam, India
}

\section{Article history:}

Submission July 2020

Revised January 2021

Accepted March 2021

*Corresponding author:

E-mail: nnirjan@gmail.com

\begin{abstract}
Heavy metal pollution in the aquatic ecosystem poses a serious threat to the human health and aquatic biodiversity around. There is urgent need to remediate heavy metals contaminated wastewater through eco-friendly ways. Fungi and other microorganisms have been reported to have promising potential to remove heavy metals from wastewater through biosorption. Thus, the present work aimed to isolate tolerant fungal species from different sites of a polluted river Bharalu in Assam. After preliminary screening, out of a total of 15 fungal isolates obtained, 4 isolates Aspergillus niger, Aspergillus flavus, Aspergillus fumigatus, and Colletotrichum gloeosporioides were selected for further study. Tolerance limit of the isolates for Cadmium (Cd) was carried out at concentrations ranging from $100 \mathrm{ppm}$ to $1000 \mathrm{ppm}$. Results showed that the maximum tolerance was observed in C. gloeosporioides, followed by A. flavus at $400 \mathrm{ppm}$. The biosorption efficiency at $400 \mathrm{ppm}$ revealed that the maximum Cd concentration was absorbed by fungal biomass of C. gloeosporioides $(12.83 \mathrm{mg} / \mathrm{g})$ and the minimum by A. niger ( $3.91 \mathrm{mg} / \mathrm{g}$ ). Molecular identification was carried out followed by PCR amplification of the fungal biomass showing highest absorption. The sequence obtained was submitted in the GenBank using BANkIt with accession number-MN714368 which showed high similarities with C. gloeosporioides. The results indicate that isolated fungi have potential to be used to remove metals from polluted water.
\end{abstract}

Keywords: Bioremediation, Biosorption-Tolerance limit, Heavy metals, Fungi

\section{Introduction}

Because of rapid urbanization and industrialization rivers are contaminated with discharges from multiple sources. Pollution of aquatic ecosystems with heavy metals can eliminate or reduce sensitive species and may also cause an increased incidence of disease [1, 2].

These heavy metals in the environment have been a subject of great concern due to their toxicity and non-biodegradable nature. Among heavy metals, cadmium (Cd) needs special attention as it is one of the most toxic, non-essential trace elements [3]. It is released to the environment by mine tailing, tannery, electroplating industries, etc., which can pose a severe threat to human health [4].

Bharalu is a small tributary of the Brahmaputra River in Assam, India, which flows through the densely populated areas of Guwahati city. The river receives wastewater from urban run-off, sewage discharge, etc. The State Pollution Control Board of Assam has marked Bharalu as one of the most polluted tributaries. Moreover, the pollution level of Bharalu is regarded as one of the significant sources of contamination affecting the overall quality of the river Brahmaputra. Previous records revealed that Bharalu in Assam had been a central contaminated area with a high percentage of heavy metals, mainly lead, chromium, cadmium [5].

At present, there are various physicochemical methods available for the remediation of different toxic chemicals from water. However, these methods are expensive, limited applications, and may produce toxic by-products [6]. Studies have found that microorganisms can be used as biological adsorbents to remove toxic metals from wastewater at low cost and in an eco-friendly way [6, 7]. Mycoremediation is a bioremediation technique that 
employs fungi to remove toxic chemicals and is considered effective, economical, and environmental friendly. Fungi are osmo-heterotrophic eukaryotes having high potential to produce an extensive variety of organic acids and extracellular enzymes. The fungal biomass can act as an effective biosorbent against toxins and xenobiotic components [8]. The removal of heavy metal by the fungal biomass is a much better way than conventional adsorbent techniques low-cost-technology. Therefore, there is an urgent need for the screening of high tolerant fungi from contaminated areas. In this study, an attempt has been made to isolate and evaluate the biosorption capacity of $\mathrm{Cd}$ tolerant fungi from the river Bharalu.

\section{Material and Methods Sampling}

The water samples were collected from Bharalu tributary, Guwahati, Assam, 2019. A total of 3 water samples (upstream, downstream, near the roadside bridge) were collected respectively from different spots separated by 3-5 km distance from each other to cover a high range of metal contamination. The parameters were analyzed at the Environmental Research Laboratory, Department of Environmental biology and Wildlife Sciences, Molecular Biology and Biotechnology Research Laboratory, Department of MBBT, Cotton University, Guwahati. The samples were maintained at or below $4^{\circ} \mathrm{C}$.

\section{Isolation and identification of fungi}

Isolation of fungi was done by Serial dilution and spread over potato dextrose agar (PDA) prepared plates [7] with minor modifications. The plates were then incubated for seven days at $27 \pm$ $3^{\circ} \mathrm{C}$ and observed for the development of colonies.

\section{Morphological identification of fungi}

The purified fungal isolates were identified based on their macroscopic and microscopic characteristics and stained with LPCB staining $[9,10$, $11]$.

\section{Screening of heavy metal-tolerant fungi}

The fungal strains were screened for determining the tolerance limits to $\mathrm{Cd}$. A small quantity of mycelium was inoculated on PDA plates supplemented individually with $25 \mathrm{ppm}$ concentration of trace metal and incubated at $28 \pm 3^{\circ} \mathrm{C}$ for seven days with slight modification. The growth of the strains was observed and tolerance indices were determined by measuring the radius of colony extension against control (without the heavy metal Cd) $[7,12]$.

$$
\text { Tolerance Index }=\frac{I}{N I}
$$

Note: I stands for radial growth (mm) of test fungus in heavy metal incorporated medium; NI stands for radial growth (mm) of test fungus in non-incorporated medium

\section{Determination of tolerance limits of Cadmium}

To determine the tolerance limit, each fungal strain was grown in PDA plates in triplicates with different concentrations of Cd ranging from 100 ppm to $1000 \mathrm{ppm}(100,400,600,800$, and 1000) and incubated at $27 \pm 3^{\circ} \mathrm{C}$ for 7 days. The PDA plate without $\mathrm{Cd}$ was taken as the control. The lowest metal concentration determined the minimum inhibitory concentration that inhibits the visible growth of the fungal isolates.

Prior to the assay, the isolates capable of growing at the maximum concentration were grown in Potato dextrose (PD) broth in triplicates for further screening for biosorption efficiency of Cd. Un-inoculated strains containing PD broth of maximum concentration of heavy metal served as the control [7].

\section{Assessment of cadmium level in fungal isolates}

To evaluate the biosorption capacity of fungal biomass, levels of Cd were determined in the isolates using AAS (ECIL, 4129) after acid digestion [7]. The fungal isolates in the broth were harvested through filtration using Whatman filter. The harvested fungal biomass was acid digested by washing with double distilled water 2-4 times with some minor modification for determination of biosorption capacity of a metal. Acid digestion was performed using US EPA method 3050B [13] and the details of the methodology are described elsewhere [14]. The uptake of heavy metal by fungal biomass was calculated using the following equation:

$$
\text { qe }\left(\frac{\mathrm{mg}}{\mathrm{g}}\right)=\frac{C \times V \times 1000}{W}
$$

Note: $\mathrm{q}_{\mathrm{e}}$ concentration of heavy metal $\mathrm{Cd}$ accumulated by fungal biomass $(\mathrm{mg} / \mathrm{g})$; C concentration of heavy metal (ppm); V (ml) the volume of the aqueous 


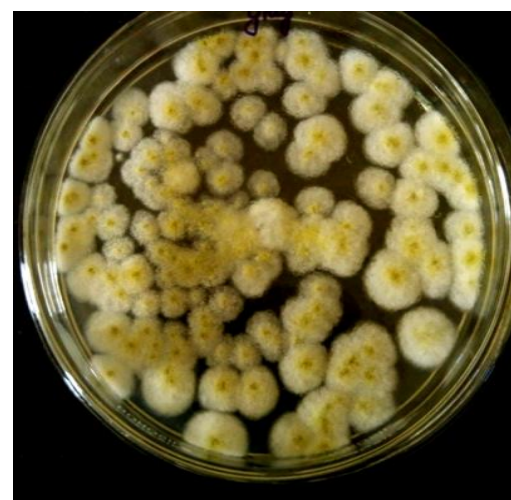

(a)

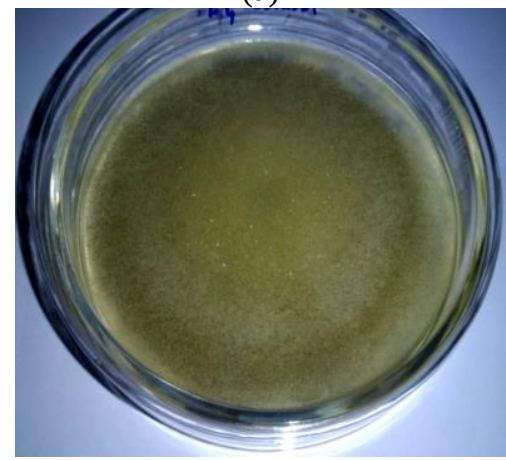

(c)

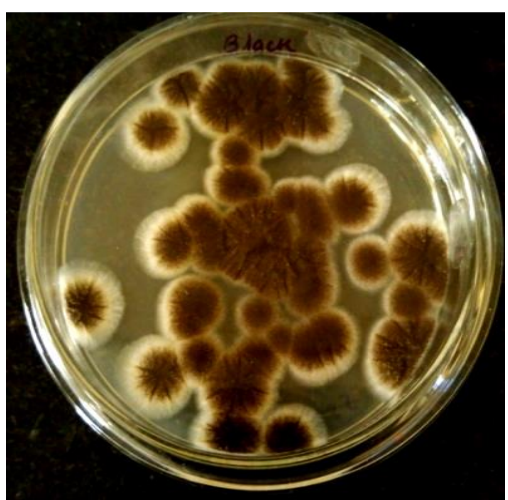

(b)

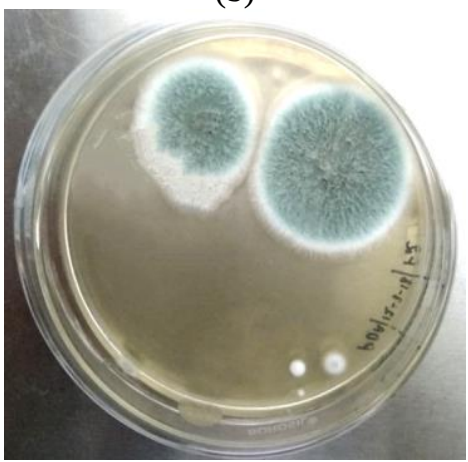

(d)

Figure 1. Pure culture of the fungal isolates, (a) Aspergillus flavus, (b) Aspergillus niger, (c) Colletotrichum gloeosporioides, and (d) Aspergillus fumigatus

medium and $\mathrm{W}(\mathrm{g})$ is the dry weight of the fungal biomass.

\section{Identification of Cadmium tolerant fungi}

Isolation of fungal genomic DNA: Isolation of fungal genomic DNA was carried out by CTAB method [15, 16, 17]. The DNA pellets were dissolved in $30 \mu \mathrm{lE}$ and were further preserved in $20^{\circ} \mathrm{C}$. PCR Amplification: The DNA obtained after isolation was additionally stored at $-4^{\circ} \mathrm{C}$ for amplification. The PCR was performed for the fungus using the primers ITS4 (3'TCCTCCGCTTAGATATGC-5') and ITS5 (3'GGAAGTAAAAGTCGTAACAAGG-5’) [12, 18]. The reaction mixtures were performed for 20 $\mu \mathrm{L}$ final volume for different concentrations DNA. The fungus showing the highest biosorption was sent for sequencing deposited in the NCBI GenBank database using BankIT.

\section{Results and Discussions}

In the present work, the main aim was to evaluate the tolerant fungi capable of Cd biosorption. Different species of fungi were isolated from three different sites of river Bharalu. A total of 15 isolates were recovered and were identified by their microscopic characteristics. Preliminary screening was done for the isolates at $25 \mathrm{ppm}$ concentration of heavy metal Cd, followed by a tolerance limit of Cd ranging from $100 \mathrm{ppm}$ to $1000 \mathrm{ppm}$. Out of 15 isolates, 4 isolates Aspergillus niger, Aspergillus flavus, Aspergillus fumigatus, and Colletotrichum gloeosporioides (Figure 1) showed higher tolerance limits towards $\mathrm{Cd}$ and these species were selected for further study. The results indicated that at higher concentrations of $\mathrm{Cd}$, the growth of other fungal isolates gets inhibited.

The maximum tolerance index was observed in C. gloeosporioides about $8.8 \mathrm{~mm}$ (Figure 2), followed by A. flavus about $5.8 \mathrm{~mm}$ at $400 \mathrm{ppm}$. All four isolates were able to tolerate $\mathrm{Cd}$ at a concentration of $400 \mathrm{ppm}$. Similar work was performed for the removal of heavy metals $\mathrm{Pb}, \mathrm{Cd}$, $\mathrm{Cr}$, and Ni [7]. Out of total 76 isolates, A. niger, Trichoderma longibrachiatum, $A$. flavus were able to tolerate up to $400 \mathrm{ppm}$ concentration [7]. Another work was recorded for the biosorption of Cd by filamentous fungi. The biosorption efficiency of Cd was shown by a species of Penicillium and a genus of Aspergillus [8].

As can be seen in (Figure 3) at Cd concentra- 


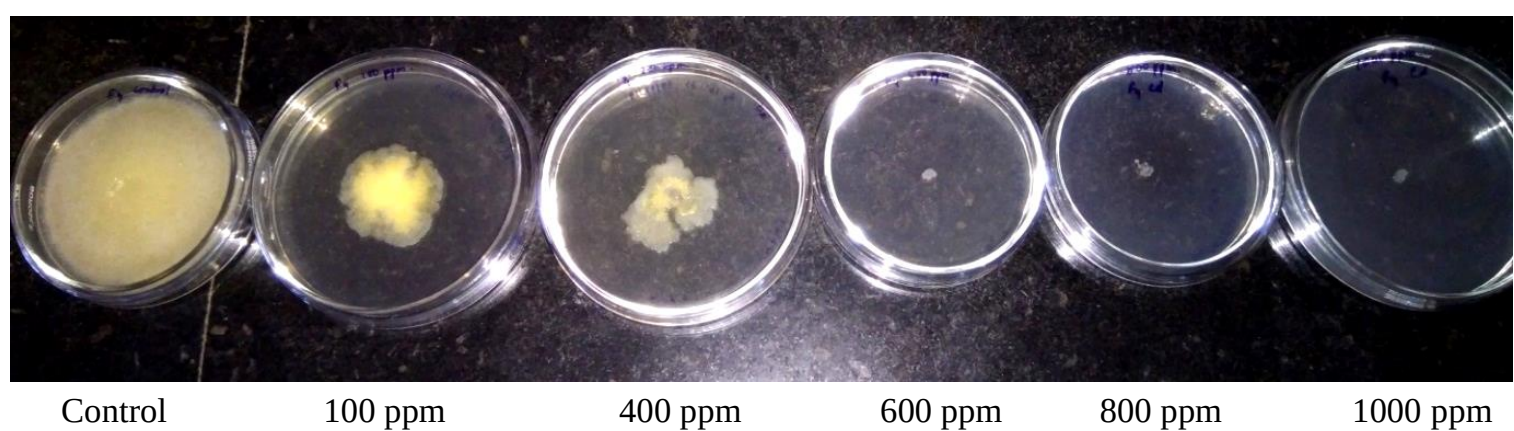

Figure 2. Growth of Colletotrichum gloeosporioides fungus after exposure to different concentration of Cd

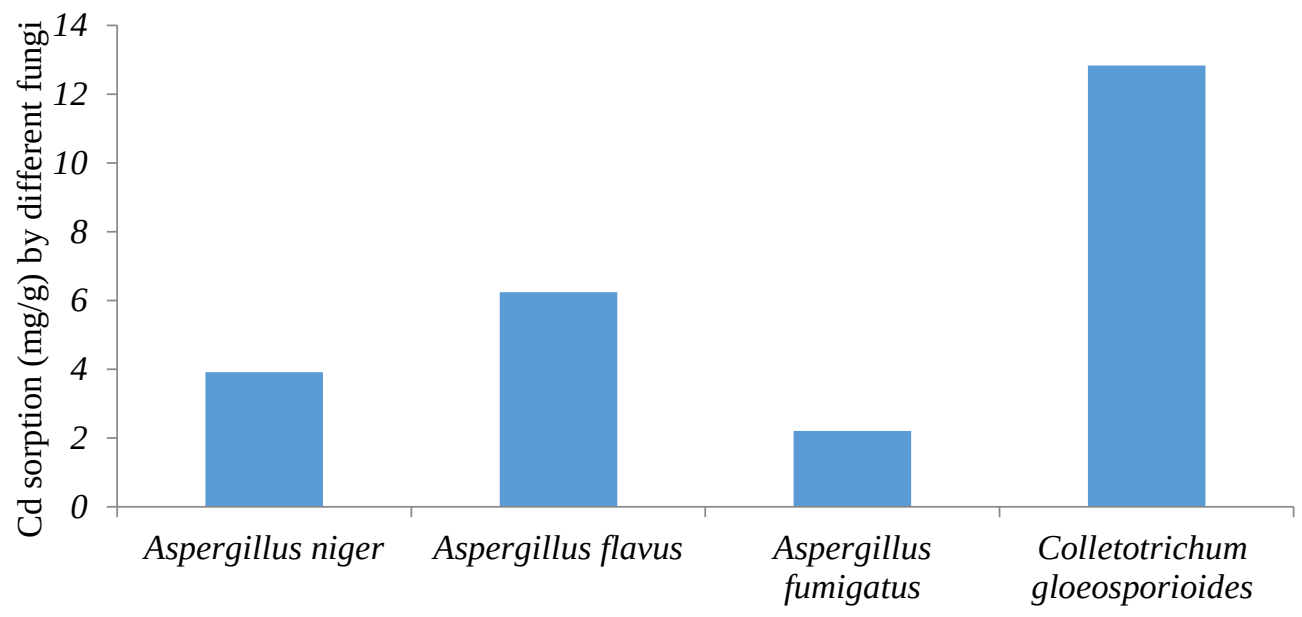

Figure 3. Uptake of Cd in mg/g by different fungal biomass from liquid medium containing 400 ppm Cd

tion of $400 \mathrm{ppm}$ - the maximum uptake was observed in C. gloeosporioides (12.83 $\mathrm{mg} / \mathrm{g})$ followed by $A$. flavus (6.24 mg/g). The minimum uptake was observed in $A$. niger (3.91 mg/g) (Figure 3). Joshi et al. recorded similar results in the biosorption of different heavy metals at 50 ppm. The maximum uptake of lead $(\mathrm{Pb})$ was observed in $A$. terreus and the minimum uptake of $\mathrm{Pb}$ was found in A. niger [7]. For $\mathrm{Cd}$ the maximum uptake was observed in Trichoderma viride and minimum was observed in Aspergillus awamori. Another work was recorded in Tangier, Morocco for biosorption of Cd [19]. A total of 36 microorganisms were isolated from heavy metal contaminated site. The results revealed that most of the isolates were resistant to $\mathrm{Pb}, \mathrm{Cr}, \mathrm{Cu}, \mathrm{Cd}$ and $\mathrm{Zn}$. Out of the total isolates, Aspergillus and Penicillium showed the maximum tolerance towards all the heavy metals. In addition, Rodriguez et al., Dwivedi et al. reported similar work for bioremoval of different heavy metals by resistant fungus $A$. niger and $A$. flavus [20, 21].

Molecular identification was done for the iso- lates followed by PCR amplification using primers ITS4 and ITS5 in the current study. Different amplified products were obtained ranged from $550-600 \mathrm{bp}$. The amplified product of the fungus showing highest biosorption of $\mathrm{Cd}$ was sent for sequencing and was submitted in GenBank using BANkIt with accession number-MN714368. It showed high similarities with $C$. gloeosporioides. Similar results have been reported from the gold and gem-stone mining sites. A total of 3 different heavy metal tolerant indigenous species Fomitopsis meliae, Trichoderma ghanense, and Rhizopus microsporus were isolated from the mining sites [12]. In addition, Fazli et al. confirmed the presence of highly Cd tolerant fungi isolated from cadmium-polluted sites. Out of total seven isolates, Aspergillus versicolor was found to show highest biosoprtion towards Cd [4]. Another work was carried out for screening of filamentous fungi with various trace metals. A total of 14 fungal strains were identified using ITS of rDNA belonged to genus Aspergillus, Trichoderma, Fusarium, Rhizomucor, Cunninghamella, 
Hypocrea, Cladosporium, Penicillium, and Simplicilillium [22].

\section{Conclusion}

Indigenous fungal species were isolated from the Bharalu which exhibited remarkable tolerance against heavy metal $\mathrm{Cd}$. Exposures of the isolates A. niger, A. flavus, A. fumigatus, and C. gloeosporioides to elevated Cd levels revealed the high tolerance capacity. The maximum tolerance index was observed in case of $C$. gloeosporioides about $8.8 \mathrm{~mm}$ at $400 \mathrm{ppm}$ followed by $A$. flavus. The maximum Cd biosorption efficiency at $400 \mathrm{ppm}$ was observed in C. gloeosporioides (12.83 mg/g). In presence of high $\mathrm{Cd}$ concentration, the fungus showed a high potential to grow actively and aid in biosorption. The minimum absorption efficiency was observed in A. niger (3.91 mg/g). Molecular identification was carried out followed by PCR amplification of the fungal biomass showing highest absorption. The sequence obtained was submitted in the GenBank using BANkIt with accession number-MN714368. It showed high similarities with C. gloeosporioides. This study revealed a much promising and potential applicability of fungus for Cd biosorption and detoxification. Although biosorption is still in its preliminary stages, further detailed study needs to be done to explore its eco-friendly management of heavy metals.

\section{Acknowledgment}

\section{References}

1. Wu RSS, Lau TC, Fung WKM et al. (2007) An artificial mussel for monitoring heavy metals in a marine environment. Environment Pollution 145 (1): 104-110. doi: 10.1016/j.envpol.2006.03.053.

2. Kibria G, Lau TC, Wu R (2012) Innovative 'Artificial Mussels' technology for assessing spatial and temporal distribution of metals in Goulburn-Murray catchments waterways, Victoria, Australia: Effects of climate variability (dry vs. wet years). Environment International 1(50): 38-46. doi: 10.1016/j.envint.2012.09.006.

3. Wang G, Wang L, Ma F et al. (2019) Integration of earthworms and arbuscular mycorrhizal fungi into phytoremediation of cadmium-contaminated soil by Solanum nigrum L. Journal of Hazardous Materials 389: 121873. doi: 10.1016/j.jhazmat.2019.121873.

4. Fazli MM, Soleimani N, Mehrasbi M et al. (2015) Highly cadmium tolerant fungi: their tolerance and removal potential. Journal of Environmental Health Science \& Engineering 13:19. doi: 10.1186/s40201-015-0176-0.

5. Roy S, Kalita JC (2011) Identification of Estrogenic Heavy metals in Water Bodies Around Guwahati City,
Assam, India. International Journal of ChemTech Research 3 (2): 699-702. ISSN: 0974-4290.

6. Bai SR, Abrahim TE (2003) Studies on chromium (VI) Adsorption-desorption using immobilized fungal biomass. Bioresource Technology 87(1): 17-26. doi: 10.1016/s0960-8524(02)00222-5.

7. Joshi PK, Swarup A, Maheshwari S et al. (2011) Bioremediation of Heavy Metals in Liquid Media Through Fungi Isolated from Contaminated Sources. Indian Journal of Microbiology 51 (4): 482-487. doi 10.1007/s12088-011-0110-9.

8. Manguilimotan LC, Bitacura JG (2018) Biosorption of cadmium by filamentous fungi isolated from coastal water and sediments. Journal of Toxicology. doi: 10.1155/2018/7170510.

9. Kornerup A, Wansher JH (1978) Methuen Handbook of Colour, Eyre Methuen 3:252.

10. Silva DM, Batista LR, Rezende EF et al. (2011) Identification of Fungi of The Genus Aspergillus Section Nigri Using Polyphasic Taxonomy. Brazilian Journal of Microbiology 42: 761-773. doi: 10.1590/S151783822011000200044.

11. Shamly V, Kali A, Srirangaraj S, Umadevi S (2014) Comparison of Microscopic Morphology of Fungi Using Lactophenol Cotton Blue (LPCB), Iodine Glycerol and Congo Red Formaldehyde Staining. Journal of Clinical and Diagnostic Research 8 (7). doi: 10.7860/JCDR/2014/8521.4535.

12. Oladipo OG, Awotoye OO, Olayinka A, Bezuidenhout CC, Maboeta MS (2018) Heavy metal tolerance traits of filamentous fungi isolated from gold and gemstone mining sites. Brazilian journal of microbiology 49: 29-37. http://www.bjmicrobiol.com.br/.

13. EPA US, (1996) Method 3050B: acid digestion of sediments, sludges, and soils. Environ. Prot. Agency 2, 3e5.

14. Chabukdhara M, Nema AK (2012) Assessment of heavy metal contamination in Hindon River sediments: A chemometric and geochemical approach. Chemosphere 87(8): 945-53. doi: 10.1016/j.chemosphere.2012.01.055.

15. Doyle JJ, Doyle J L (1987) A rapid DNA isolation procedure for small quatities of fresh leaf tissue. Phytochemical Bulletin 19: 11-15.

16. Tripathy SK, Maharana M, Ithape DM et al. (2017) Exploring Rapid and Efficient Protocol for Isolation of Fungal DNA. International Journal of Current Microbiology and Applied Sciences 6 (3): 951-960.

17. Umesha S, Manukumar H.M, Raghava S (2016) A rapid method for isolation of genomic DNA from food-borne fungal pathogens. Biotechnology 6 (2): 123. doi10.1007/s13205-016-0436-4.

18. White TJ, Bruns T, Lee S, Taylor JL (1990) Amplification and Direct Sequencing of fungal ribosomal RNA genes for phylogenetics. PCR protocols:a guide to methods and applications 18: 315-322.

19. Ezzouhri L, Castro E, Moya M et al. (2009) Heavy metal tolerance of filamentous fungi isolated from polluted sites in Tangier, Morocco. African Journal of Microbiology Research 3 (2): 35 - 48.

20. Rodriguez IA, Cardenas-Gonzalez JF, Perez Adriana SR et al. (2018) Bioremoval of Different Heavy Metals by the Resistant Fungal Strain Aspergillus niger. Bioinorganic Chemistry and Applications. doi: 10.1155/2018/3457196. 
21. Dwivedi S, Mishra A, Saini D (2012) Removal of Heavy Metals in Liquid Media through Fungi Isolated from Waste Water. International Journal of Science and Research (IJSR) 1 (3): 181 - 185.

22. Sharma, GD, Mohamed H (2014). Isolation and Screening of Some Filamentous Fungi with Various Trace Metals. Microbiology 4 (2). doi: 10.15373/2249555X/FEB2014/16 .
23. Veglio F, Beolcmi F (1997) Removal of metals by biosorption: a review. Hydrometallurgy 44: 301-316. doi: 10.1016/S0304-386X(96)00059-X.

24. Joo JH and Hussein KA (2012) Heavy Metal Tolerance of Fungi Isolated from Contaminated Soil. Korean Journal of Soil Science and Fertilizer 45 (4): 565-571. doi: 10.7745/KJSSF. 